\title{
Da invenção da "fronteira" à crise das expectativas ficcionais sobre o desenvolvimento na região amazônica
}

\section{From the invention of the "frontier" to the crisis of fictional expectations about development in the Amazon region}

Pedro Frizo - Mestre em Sociologia, pela Universidade Federal do Rio Grande do Sul (UFRGS). E-mail: pedro.frizo@gmail.com

Paulo Niederle - Doutor em Ciências Sociais, pela Universidade Federal Rural do Rio de Janeiro (UFRRJ). Professor da Universidade Federal do Rio Grande do Sul (UFRGS). E-mail: pauloniederle@gmail.com

\section{Resumo}

Um dos principais projetos encabeçados pelo regime militar brasileiro foi a colonização da Amazônia, que estimulou a ocupação massiva deste território, mobilizando enormes contingentes de indivíduos das mais diferentes regiões do país. O objetivo deste artigo é compreender os mecanismos discursivos para a produção das migrações para a Amazônia, atentando-se à sua produção e sua materialização nas práticas e significações dos atores sociais. A partir da análise de documentos da Biblioteca Nacional do Exército e de entrevistas com assentados do Projeto de Assentamento Dirigido Rio Juma, no município de Apuí, procedeu-se uma análise documental e qualitativa dos textos e das falas dos interlocutores, apoiando-se na análise e agrupamento temático dos dados, a fim de encontrar significações em comum sobre o território e as migrações para o mesmo. Os resultados demonstram que a colonização esteve apoiada na formação e produção de expectativas individuais a partir do discurso estatal, o qual fundamentou a construção de um "futuro imaginado" sobre a Amazônia como território de ascensão social e econômica. Com efeito, concedeu a esta região um significado que legitimou a formação de um regime institucionalizado de espoliação dos seus recursos naturais.

\section{Palavra-chave}

Fronteira. Expectativas Ficcionais. Colonização. Assentamentos.

\begin{abstract}
One of the main projects led by the Brazilian military regime was the colonization of the Amazon, which stimulated the massive occupation of this territory, mobilizing huge contingents of individuals from the most different regions of the country. The objective of this article is to understand the discursive mechanisms for the production of migrations to the Amazon, paying attention to their production and their materialization in the practices and meanings of social actors. Based on the analysis of documents from the National Army Library and interviews with settlers of the Rio Juma Directed Settlement Project, in the municipality of Apuí, a documentary and qualitative analysis of the texts and speeches of the interlocutors was carried out, based on the analysis and thematic grouping of data, in order to find common meanings about the territory and the migrations to it. The results show that colonization was supported by the formation and production of individual expectations based on the state discourse, which supported the construction of an "imagined future" over the Amazon as a territory of social and economic ascension. Indeed, it gave this region a meaning that legitimized the formation of an institutionalized regime for the plundering of its natural resources.
\end{abstract}

\section{Keywords}

Frontier. Fictional expectations. Colonization. Settlements. 


\section{INTRODUÇÃO}

A história de Aurélia ${ }^{1}$ na Amazônia começou em 1983, quando ela e o marido Eliseu saíram das adjacências de Francisco Beltrão (PR) rumo ao Projeto de Assentamento Dirigido Rio Juma (PA Juma), no sul amazonense. Ambos faziam parte do Movimento dos Filhos dos Agricultores Sem-Terra, o qual foi formado por indivíduos cujas propriedades haviam sido alagadas para a construção de uma barragem. Em uma reunião promovida por agentes do Instituto Nacional de Colonização e Reforma Agrária (INCRA), Aurélia e Eliseu tomaram conhecimento do PA Juma: "um local desprovido de malárias e com ampla abundância de terras" (informação verbal'). Dias depois, os dois se despediram de suas famílias e rumaram à Amazônia em busca de melhores condições de vida.

A história de Aurélia não é um caso extraordinário. Com algumas nuanças, ela se repete nas falas dos inúmeros indivíduos que compuseram os projetos de assentamento na Amazônia brasileira, em especial naqueles criados durante o regime militar (1964-1985). Quando tomadas em conjunto, essas histórias têm em comum dois componentes narrativos: (i) a presença de um discurso estatal sobre o território amazônico, e (ii) a consequente construção de expectativas entre as populações envolvidas nos processos de ocupação deste território. Em conjunto, discurso e expectativa definem uma projeção de futuro e sua respectiva materialização em práticas, rotinas, hábitos e procedimentos que buscam efetivar a profecia do desenvolvimento no local ocupado. Neste sentido, entender o futuro imaginado para a Amazônia brasileira, seja o ideal concebido e reproduzido pelo governo militar, seja o ideal aspirado pelos colonos, auxilia na compreensão da gênese das formas de apropriação e exploração dos elementos naturais deste território.

Portanto, o objetivo deste artigo é compreender a construção discursiva do Estado sobre o território amazônico, bem como o processo de subjetivação deste discurso entre os atores sociais que formaram parte do intenso movimento migratório para a região a partir dos anos 1970, em especial com os projetos de colonização dirigida.

O artigo está estruturado em seis seções, além desta introdução. Na próxima, posicionamos as "expectativas ficcionais" (BECKERT, 2016) como conceitochave para compreender a gênese do movimento migratório à Amazônia durante sua colonização na segunda metade do século XX. Em seguida, apresentamos o

\footnotetext{
Todos os nomes próprios apresentados ao longo do artigo são fictícios.

2 Informação concedida por Eliseu, em fevereiro de 2017.
} 
percurso metodológico da pesquisa. Segue a isso uma análise da construção do discurso estatal sobre a colonização da Amazônia. Subsequentemente, a partir das entrevistas realizadas junto aos atores do PA Juma em 2017, elucidam-se as principais expectativas dos colonos migrantes e como estas se conectam com o discurso do Estado sobre a região. Associado a isto, demonstramos a crise das expectativas ficcionais e da narrativa do desenvolvimento, o que não significa, contudo, a sua substituição por uma nova narrativa. $\mathrm{O}$ artigo conclui demonstrando que um dos principais dilemas dos atores sociais do território diz respeito exatamente à incapacidade da narrativa colonizadora, ainda vastamente dominante, de engajar os atores sociais em torno de um novo projeto de futuro.

\section{PRODUÇÃO DE EXPECTATIVAS FICCIONAIS COMO ALAVANCA DO DESENVOLVIMENTO}

No começo dos anos 1960, Albert Hirschman, um dos principais estudiosos das economias latino-americanas, sugeriu que "o desenvolvimento não depende tanto de encontrar ótima confluência de certos recursos e fatores de produção, quanto de provocar e mobilizar, com propósito desenvolvimentista, os recursos e as aptidões que se acham ocultos, dispersos ou mal-empregados" (HIRSCHMAN, 1961, p. 19). Segundo o autor, estes recursos ocultos não eram os minérios escondidos abaixo da terra, mas as "racionalidades ocultas", ou seja, os mecanismos cognitivos e normativos que catalisam a ação coordenada de desenvolvimento. Assim, diferentemente dos economistas heterodoxos da época, em particular daqueles que acentuavam os bloqueios impostos pelo modelo dependentista que havia se consolidado na região, Hirschman procurava reconhecer como determinadas mudanças sociopolíticas e institucionais poderiam conter o embrião de profundas transformações societárias. Com efeito, o autor fala em uma "arte de promover o desenvolvimento", e de impulsionar os atores a participar de uma "aventura épica" onde nada é certo, claro ou absoluto (HIRSCHMAN, 1996).

Os governos militares existentes no Brasil entre 1964 e 1985 parecem ter compreendido a lição de Hirschman e, em que pese este fosse um entusiasta da democracia, utilizaram de sua contribuição para reconstruir a narrativa desenvolvimentista ${ }^{3}$ de colonização da Amazônia. No centro desta narrativa

\footnotetext{
Encontramos em Fonseca (2004) a definição sobre "desenvolvimentismo" que associamos à ação coordenada do Estado de ocupação sistemática da Amazônia. Para o autor, há quatro dimensões fundamentais para a compreensão do termo: (i) a legitimação da intervenção do Estado para impulsionar o crescimento econômico; (ii) um ideal nacionalista como legitimador da intervenção estatal, assim como um entendimento comum sobre o Estado como uma
} 
esteve a produção de ideias e valores que funcionaram como "enquadramentos" (GOFFMAN, 2012) não apenas das políticas públicas, mas para a mobilização dos indivíduos dentro do processo de desenvolvimento nacional.

Enquanto ator central na produção de instituições, aqui incluídos os referenciais cognitivos e normativos da ação (DIMAGGIO; POWELL, 2005; SCOTT, 2014), o Estado assume um papel central na orientação das trajetórias socioeconômicas. Disputado por diferentes grupos e coalizões políticas, os quais visam justamente à possibilidade de controlar a produção das instituições, o Estado pode ser definido como um agregado de dispositivos que definem as diferentes estruturas organizacionais que "colocam o Estado em ação", tais como ministérios, autarquias públicas, escolas e justiça. Por sua vez, amparados pela autoridade e legitimidade dos dispositivos institucionais, estas organizações produzem não apenas leis, regulamentos administrativos, rotinas técnicas e políticas públicas, mas também narrativas e expectativas sobre o desenvolvimento, as quais retroalimentam a legitimidade dos dispositivos e dos atores que os controlam. Neste sentido, a produção de instituições se dá como o método de "controle social” (ELIAS, [1939] 1994; TAVARES DOS SANTOS, 2004), o qual é exercido sobre diferentes grupos sociais e lastreado em diferentes mecanismos de coerção.

Já está amplamente evidente na literatura que a colonização da Amazônia se inseriu em um projeto desenvolvimentista de escala nacional (IANNI, 1979; TAVARES DOS SANTOS, 1991; VELHO, 2009), com ampla intervenção estatal para a implementação deste projeto. No entanto, como podemos identificar os dispositivos de controle promovidos pelo regime militar e, mais particularmente, os dispositivos cognitivos e subjetivos que operacionalizaram um movimento migratório em massa?

Para responder esta questão, nossa pesquisa focalizou a produção textual feita por representantes do Estado a respeito da Amazônia, a fim de capturar as dimensões do discurso estatal sobre aquele território, bem como as subjetividades entre os atores sociais envolvidos diretamente neste processo. Uma vez que o discurso exibe íntima associação com a produção de rotinas, lógicas de ação, crenças e valores compartilhados entre os indivíduos, compreender a produção discursiva e a sujeição individual a um discurso insere-se na tarefa de jogar luz à gênese das instituições cultural-cognitivas: instâncias de crucial função no que diz respeito ao controle social sobre os anseios, as motivações e as expectativas dos indivíduos envolvidos na colonização da Amazônia.

das máximas instâncias representativas da nação; (iii) uma noção compartilhada sobre a história como um processo positivo e de gradativa melhoria; e (iv) a reprodução da ideia de industrialização como o único caminho possível para alcançar a modernidade. 


\section{O PERCURSO METODOLÓGICO DA PESQUISA}

O Projeto de Assentamento Dirigido Rio Juma (PA Juma) foi tomado como o recorte empírico deste estudo. Constituído em 1982, na época de sua criação era o maior assentamento rural da América Latina, com mais de 670 mil hectares e com capacidade planejada para receber algo em torno de 7,5 mil famílias. Os primeiros migrantes, em sua ampla maioria, se originavam da região Sul do país, especialmente do oeste paranaense, os quais migraram especialmente devido a dificuldades de reprodução social em suas terras de origem. Condições precárias de assistência técnica à produção rural e comercialização, somadas ao desordenamento fundiário e a um expressivo isolamento social, levaram muitos dos primeiros migrantes a rumarem a outras regiões, o que faz do PA Juma um assentamento com ocupação efetiva de aproximadamente $20 \%$ em relação ao seu potencial original (FRIZO, 2019) ${ }^{4}$.

Entre janeiro e março de 2017, conduzimos uma pesquisa de campo no município de Apuí, sul do estado do Amazonas, onde se localiza o PA Juma. Ao todo, 23 famílias rurais participaram de entrevistas semiestruturadas, bem como preencheram questionários concebidos exclusivamente para a realização da pesquisa. Além disso, outros oito funcionários de organizações não governamentais $(\mathrm{ONG})$ atuantes no município, e quatro agentes públicos, responderam às entrevistas e questionários.

Ambas as fontes permitiram coletar, principalmente, os dados relacionados às expectativas dos atores sociais do PA Juma frente ao processo de migração, ainda nos anos de 1980 e 1990. Embora, a partir deste material, algumas considerações sobre a ação estatal também foram levantadas, este foi insuficiente para compreender a construção de um "futuro imaginado" por parte do Estado para o território amazônico. Com isso, precisávamos de dados que nos pudessem informar a produção discursiva estatal. Para tanto, trabalhou-se em dois documentos publicados em 1971 pela Biblioteca Nacional do Exército (BNE), a saber: "A Amazônia e Nós" e "Problemática da Amazônia". Ambos os livros representam satisfatoriamente o zeitgeist do governo militar brasileiro frente

\footnotetext{
Historicamente, a formação agropecuária do assentamento foi marcada por uma "substituição produtiva": gradativamente, a agricultura temporária cedeu espaço para a pecuária extensiva, posicionando o PA Juma e o município de Apuí, como um todo, como uma das cidades com o maior número de cabeças de gado no Amazonas (FRIZO; NIEDERLE, 2019). Com efeito, as taxas de desmatamento na região cresceram expressivamente desde os anos 1990, período em que se iniciou a atividade pecuária em maior escala. No final de 2019, o município ficou nacionalmente conhecido pelo aumento vertiginoso nas queimadas sobre a floresta amazônica, apresentando um incremento nos meses de julho e agosto daquele ano, se comparado ao mesmo período de 2018, de 228\% (IDESAM, 2019).
} 
à ocupação maciça da Amazônia, contendo informações, dados e significações que dizem muito sobre o "futuro imaginado" que pretendemos investigar".

No que diz respeito às técnicas de análise dos dados, foi conduzida uma análise de conteúdo sobre o material coletado, priorizando-se a análise temática como método de agrupamento de significações comuns sobre o território e o movimento migratório (BARDIN, 1971). Todos os dados levantados a partir das entrevistas foram separados em categorias analíticas, as quais totalizaram 25 ao final do estudo. Essa separação foi feita com o intuito de discriminar os dados segundo as dimensões da vida social manifestadas pelos atores entrevistados, diferenciando relatos que se distinguiam em termos de conteúdo e problemática abordada.

Nas categorias analíticas referentes à criação do assentamento e o processo migratório, a análise temática norteou a criação de conjuntos temáticos específicos e delimitados por graus de frequência de manifestação (CAVALCANTE et al., 2014). Tais conjuntos permitiram o delineamento de diferentes achados sobre os discursos e subjetividades envolvidas com a produção social da migração, tais como: (i) razões socioeconômicas para a migração; (ii) condições de vida e de reprodução social no campo nos locais de origem; (iii) significações e narrativas estatais sobre o espaço geográfico amazônico; (iv) práticas estatais de engajamento e mobilização de migrantes na região Sul; e (v) criação do assentamento e condição de vida nos primeiros anos. A fim de apoiar-nos na sistematização dos dados e em seu agrupamento temático, utilizou-se do software NVivo 11.

\section{A PRODUÇÃO ESTATAL DA COLONIZAÇÃO: A "INVENÇÃO” DA FRONTEIRA COMO LUGAR DO DESENVOLVIMENTO}

De maneira introdutória, a principal consideração a ser feita sobre os dois livros diz respeito à "invenção" do território amazônico como local propício à ocupação, especialmente a partir da sustentação de uma visão "híbrida" sobre a sua configuração cultural, econômica, política e social. Uma série de categorias são mobilizadas ao longo das duas obras para a sustentação deste hibridismo, contrastando o caráter "selvagem" desta região ao projeto "moderno" proposto pelo Governo militar. Já na primeira leitura, no livro "A Amazônia e Nós", a distinção feita no título entre o pronome "nós" e a região amazônica ilustra a

\footnotetext{
5 Informações mais detalhadas sobre a metodologia e o tratamento dos dados podem ser encontradas em Frizo (2019).

6 Adotamos de Escobar (1995) a ideia da "invenção simbólica e cultural” como ferramenta de controle social empregada pelo Estado para a implementação efetiva de políticas de desenvolvimento.
} 
condição dada a este lugar como território externo e estrangeiro ao mundo do autor daquele livro, desconectado da realidade social das demais regiões do país. O constante ressaltar das contradições entre os modos de vida amazônicos e os modos de vida "modernos" norteia, de maneira geral, o conteúdo disposto tanto nesse livro quanto no outro selecionado.

A fim de sustentar a ocupação da Amazônia a partir dos projetos governamentais, ambos os livros mobilizam, em um primeiro momento, expedições antigas sobre a região - tal como a de Antônio Raposo Tavares -, com o intuito de conceder linearidade e lógica à ação militar sobre aquele território. Também salta aos olhos como importantes nomes das ciências sociais brasileiras são referenciados, tais como Gilberto Freyre e Joaquim Nabuco, utilizando de relatos emitidos por tais autores como recurso textual de apoio à argumentação central dos livros sobre a virtuosidade dos grandes empreendimentos previstos para a região.

O constructo simbólico do "selvagenismo" é consolidado em diferentes frentes indutivas. Despontam uma série de significações sobre o território amazônico, as quais, em conjunto, colaboram para a construção de um sentido de urgência sobre a ocupação desta região. Mediante a infinidade de apropriações simbólicas e culturais que podem ser erguidas sobre um determinado território (ACSELRAD, 2004), as duas obras selecionadas orquestram um vasto conjunto de dados que orientam uma construção ideal acerca da Amazônia como uma "fronteira em transição" (VELHO, 2009): uma região de natureza intocada, porém à espera da ação humana para converter seus espaços geográficos e recursos em elementos passíveis de apropriação econômica e política.

Neste sentido, encontramos significações que colaboram para erguer uma imagem do território amazônico como "território fronteiriço". Em primeiro lugar, despontam as significações econômicas que projetam sobre a Amazônia a ideia de: (i) um local carente de infraestrutura; (ii) como fronteira agropecuária; (iii) mergulhado em déficits de capital que impedem investimentos públicos e privados em grande escala; (iv) imbuído de uma economia de baixo valor agregado, "meramente" extrativista; (v) e de inúmeras potencialidades econômicas a serem apropriadas e erguidas. Em segundo lugar, é apresentado um conjunto de significações sociopolíticas sobre esse território, as quais se apoiam na ideia da região como (vi) um local plausível de ocupação estrangeira devido ao seu (vii) "vazio demográfico", ensejando assim um projeto de povoamento maciço por parte do governo brasileiro. Por fim, pudemos encontrar um terceiro grupo de significações, mais atreladas à dimensão sociocultural, as quais entendem a Amazônia como (viii) fronteira da modernidade, onde o conhecimento científico 
ainda não avançou plenamente, bem como (ix) um território misterioso e (x) socialmente atrasado em relação às demais regiões do país.

De maneira recorrente nas duas obras, propõe-se o Estado como protagonista no avanço da fronteira, assumindo assim um "dever civilizatório" e nacional, cuja implementação efetiva ocorre a partir dos grandes empreendimentos. Ademais, se faz extensamente presente ao longo dos dois livros a ideia de que o território amazônico é permeado por diversos "distúrbios", o que consolida ao longo dos textos a ideia de haver um conjunto de necessidades objetivas e que, portanto, concedem lógica argumento de ocupação da região.

O discurso estatal recorrentemente ampara-se no termo "desenvolvimento" como significante de uma ideia modernizante e nacionalista, materializado em uma série de projetos de assentamentos, de expansão de atividades agropecuárias e industriais, de vigilância e proteção das fronteiras, de utilização do "potencial hídrico", de conversão das florestas em terras produtivas à atividade agropecuária e de integração nacional por meio da construção de estradas. Em um dos artigos do livro "Problemática da Amazônia", o coronel João Walter de Andrade, então governador do estado do Amazonas, discorre sobre uma série de “obstáculos sérios ao desenvolvimento" (ANDRADE, 1971, p. 151), os quais deveriam ser superados pelo governo. Segundo o autor, os principais "obstáculos” seriam os seguintes:

(i) a extensão física e a rarefação demográfica que concentra em 59,2\% da área total do Brasil apenas 3,7\% de sua população; (ii) o desconhecimento do potencial efetivo de recursos naturais; (iii) a escassez de recursos humanos para ocupação das fronteiras econômicas e geográficas; (iv) a debilidade do abastecimento de produtos agropecuários; (v) a ausência da mentalidade agropecuária em toda a região; (vi) a predominância da indústria do semi-artesanato, com raros enclaves de grande porte; (vii) a insuficiência de espírito empresarial, na área privada; e (viii) a falta de coordenação na atuação dos Órgãos Públicos locais (ANDRADE, 1971, p. 151, grifo nosso).

Dentre todas as dimensões do "futuro civilizado" imaginado pelo Estado militar e da complexa ideia de "um desenvolvimento para a Amazônia", a da integração nacional foi, sem dúvida, aquela que despontou como elemento protagonista. A noção de "integrar para não entregar" consolidou-se como o tecido conjuntivo das iniciativas governamentais, atrelando-se de maneira integrante no discurso nacional-desenvolvimentista do regime militar. A significação desse território como "vazio" em termos demográficos - significação esta que se constitui como eixo central do discurso integracionista - é sustentada em ambos os livros a partir de uma série de dados geográficos, físicos e populacionais. 
No livro "A Amazônia e Nós", por exemplo, o autor discute como Castello Branco, ainda em 1966, já apresentava a ideia de integração da Amazônia em seu discurso de lançamento da Operação Amazônica:

Governo e homens de empresa do Brasil, reunidos na Amazônia sob a inspiração de Deus e norteados pelo firme propósito de preservar a unidade nacional como patrimônio que receberam indiviso, conscientes da necessidade de promover o crescimento econômico acelerado da região, como processo indispensável para atingir esse objetivo e a valorização do homem que a habita: considerando que a Amazônia, com seus cinco milhões de quilômetros quadrados, correspondentes a cerca de sessenta por cento do território brasileiro, está a exigir a criação de condições para o povoamento [...] Declaram que sua aceitação maior ao desafio lançado em resposta da sua esperança, para que a Amazônia contribua através de sua perfeita e adequada incorporação à sociedade brasileira e sob a sua soberania inalienável para a solução dos grandes problemas da humanidade (MARSENO, 1971, p. 48).

A Operação Amazônica instituiu uma série de benefícios fiscais, a fim de incentivar o avanço da agropecuária e da indústria. Qualquer pessoa jurídica, por exemplo, que estivesse disposta a realizar investimentos em acordo com as demandas e projetos estatais para a região, poderia deduzir em até $50 \%$ do imposto de renda o valor efetivamente investido (MARSENO, 1971). Esta subvenção fiscal, por sua vez, reforçava o papel do Estado como agente líder no avanço das práticas capitalistas, reiterando a prática desenvolvimentista de intenso controle da política econômica do país.

Embora antes do regime militar se possa constatar uma ação planejada do Estado para a promoção de grandes empreendimentos na região amazônica - tal como a consolidação da Superintendência do Plano de Valorização Econômica da Amazônia (SPVEA), em 1953 -, foi somente a partir do golpe de 1964 que se discutiu com tamanha abrangência e empenho o "desenvolvimento" da Amazônia. A criação da Superintendência do Desenvolvimento da Amazônia (SUDAM), em 1966, representa um marco à intervenção estatal na região, bem como o Decreto n 288, de 28 de fevereiro de 1967 (BRASIL, 1967), o qual deu início à Superintendência da Zona Franca de Manaus (SUFRAMA) e ao projeto de industrialização da região.

A estes decretos, ambos os livros adicionam uma série de outros projetos que, executados em sua totalidade ou não, sustentam a abrangência do anseio desenvolvimentista para a região. Entre eles, destacam-se as hidrelétricas de Coaracy Nunes, do Rio Casca, das bacias do Xingu, do Tocantins, do Araguaia e do Madeira; as termelétricas de Belém e Manaus; e o grande lago Amazônico - 
proposta de unir as bacias do rio Orinoco e Amazonas. Por sua vez, em termos de rodovias, destacam-se os investimentos na construção da BR-364, de Cuiabá a Porto Velho; da BR-319, de Manaus a Porto Velho, da BR-230, de João Pessoa à Lábrea; da BR-174, conectando Manaus a Boa Vista; da BR-163, de Cuiabá a Santarém; da BR-010, de Belém a Brasília; da BR-316, de Teresina a Belém; e da BR-220, de Picos a Carolina.

No que tange à Zona Franca de Manaus, em um capítulo do livro "Problemática da Amazônia", redigido pelo então presidente da SUDAM, Ronaldo Franco de Sá Bonfim, o autor apresenta um conjunto de dados, dispostos ao longo do texto de tal maneira a sustentar a argumentação favorável à intervenção estatal. De acordo com o autor, havia naquele tempo uma extrema dependência regional por atividades primárias, ainda associadas com a extração de produtos madeireiros, não madeireiros e agrícolas, o que tornava, a seu ver, urgente a criação de um parque industrial que pudesse impulsionar a economia regional a maiores níveis de produtividade e produto interno bruto. $\mathrm{O}$ autor ressalta a dependência das importações de bens de consumo, o que no longo prazo tenderia a causar constantes déficits comerciais. Com todos estes dados à mão, explora a necessidade de conduzir um processo de "substituição de importações" na região amazônica, tal qual fora elaborado e proposto pelos teóricos da Comissão Econômica para o Desenvolvimento da América Latina (CEPAL) em um âmbito nacional, entre os anos de 1940 e 1950 (FURTADO, 2001).

No que diz respeito à questão agrária, o INCRA pode ser entendido como um dos agentes líderes no avanço dos assentamentos rurais - no qual a criação do PA Juma, no município de Apuí, desponta como um dentre tantos projetos de ocupação planejados por este organismo desde a sua fundação, em 1970. Segundo Ianni (1979), a colonização da Amazônia brasileira se divide em dois moldes, os quais se diferenciam entre si no que diz respeito ao modo de atuação planejada do Estado. Primeiramente, despontam as ocupações que o autor entende como colonização "espontânea", nas quais se envolveram antigos meeiros, parceiros e famílias sem-terra, advindos, em sua maioria, da região Nordeste do país. Rodovias ainda no final da década de 1950 e em meados da década de 1960, como a Belém-Brasília e a Brasília-Acre, permitiram o estabelecimento de pequenas propriedades rurais nos estados do Acre, de Rondônia e do Pará. De acordo com o autor, a colonização espontânea configura-se como uma reforma agrária não planejada, uma vez que a falta de terras aptas para a ocupação em massa no Nordeste brasileiro motivava a busca por terras "ainda não ocupadas" 7 .

\footnotetext{
Importante notar que os estados da Amazônia Legal, historicamente, já haviam passado por intensos processos migratórios, principalmente devido aos dois ciclos da borracha: o primeiro
} 
Em segundo lugar, Ianni (1979) descreve o período de colonização "dirigida" ou "planejada" como momento de atuação decisiva do Estado neste processo. O início desta fase se deu, principalmente, com a promulgação do Estatuto da Terra, a institucionalização do INCRA e a construção da BR-230 (Rodovia Transamazônica), iniciada em 1970. Estas deliberações e projetos estatais, bem como o gradativo aparelhamento do Estado para a execução dos planos de colonização e de reforma agrária, principiaram um processo de ocupação sistêmica e de larga escala da Amazônia brasileira. Especificamente no que diz respeito à construção da BR-230, por exemplo, esta abriu um amplo espaço para o povoamento, tendo em vista que a normativa referente às regras de ocupação em suas margens legalizou assentamentos ao longo de seu traçado. Segundo Almeida (1992), uma área de $100 \mathrm{~km}$ para ambos os lados da rodovia fora delineada como área prioritária para receber assentados das mais diversas regiões do Brasil.

A abertura da "fronteira" amazônica esteve envolvida em expectativas sobre as supostas potencialidades de seus recursos naturais, até então pouco usufruídas na opinião dos autores de ambos os livros. A conversão destes recursos em fatores de produção agropecuários e industriais constituía-se em uma das principais expectativas envolvendo os projetos de colonização desta região, bem como um dos principais itens a serem trabalhados pelo Estado em suas políticas públicas. Djalma Batista, importante figura pública amazonense e diretor, em 1971, do Instituto Nacional de Pesquisas da Amazônia (INPA), discorre, em um artigo do livro "Problemática da Amazônia", sobre o histórico das explorações científicas na região. $\mathrm{O}$ artigo é, nas palavras do autor, uma tentativa de sumarizar o "inventário científico da Amazônia", isto é, "o que foi feito para revelar a terra e o homem da Amazônia" (BATISTA, 1971, p. 271).

Reitera-se, ao longo deste artigo, o caráter místico do território, desenhando-o como um espaço geográfico de potenciais econômicos infinitos, porém pouco aproveitados pelo homem moderno. Djalma Batista discute ao longo de seu texto o "estoque" de recursos minerais espalhados nos estados da região Norte, as propriedades químicas de cada elemento e as suas utilidades produtivas, sanitárias e científicas. Na mesma linha argumentativa, o autor discorre sobre as potencialidades da fauna e flora amazônica, identificando-as como "recursos" pouco explorados. Também não escapa de suas considerações as possibilidades de expansão da agropecuária de larga escala a partir de práticas de calagem, adubação orgânica e adubação química. Por fim, o autor apresenta a

iniciado no final do século XIX e com fim nos anos 1910, e o segundo principiado a partir dos Acordos de Washington, em 1942, os quais deram início a uma produção maciça de borracha para a produção de armamento entre as nações Aliadas, durante a Segunda Guerra Mundial (ARAÚJO; NEVES, 2015). 
ciência como único ferramental que permite a exploração efetiva de todas estas potencialidades constrangidas, conferindo a este saber o seu valor instrumental no "futuro civilizatório" imaginado pelo Estado militar. Com efeito:

Só a ciência, porém, e sua aplicação, a tecnologia, poderão alargar os caminhos até agora apenas desbravados. Todo apoio e todos os meios precisam ser dados às instituições nacionais, que devem continuar e completar o inventário científico da Amazônia, como sentinelas decisivas da soberania e do poder de decisão do Brasil (BATISTA, 1971, p. 297).

Se a expansão de práticas capitalistas constituía eixo central no "futuro civilizado" imaginado pelo Estado, uma "revolução cultural" também formava parte integrante deste projeto. Em certa medida, a esta ideia de "revolução cultural" - que mais se associa à ideia de "epistemicídio", se se olhar a partir de um viés sociológico e antropológico - apresentava-se uma clara intenção estatal de consolidar um "espírito capitalista" na região, com vistas a superar os modos de vida das populações originárias e dos antigos posseiros entendidos como "atrasados".

Entretanto, a execução de uma "revolução cultural", conforme previa o projeto estatal, não se deu de maneira harmoniosa - e nem definitiva. Justamente ao contrário: a presença de diversos conflitos fundiários envolvendo as populações originárias e os posseiros contra as grandes empresas agrícolas, fazendeiros e compradores de terras, ilustrou - e ainda ilustra - as contradições do "projeto civilizatório" concebido pelo regime militar. No que diz respeito às iniciativas agropecuárias, por exemplo, localidades que receberam expressivas subvenções fiscais da SUDAM para a consolidação de grandes empreendimentos agropecuários estão positivamente correlacionadas ao número de assassinatos no campo, devido a conflitos envolvendo a posse da terra (COSTA, 2012). Acima de tudo, este dado demonstra que o futuro imaginado pelo Estado à região amazônica foi intimamente acompanhado pela expansão da violência, fato que reforça o caráter repressivo e autoritário do avanço da "fronteira" sobre a Amazônia - marca esta que ainda persiste nos dias de hoje.

Dessa maneira, podemos concluir esta seção com o argumento de que o futuro imaginado pelo Estado à região amazônica foi tecido em conjunto com um processo forçado de revolução cultural: deposições de antigas significações por expectativas futuras de modernização da Amazônia. A centralidade do Estado neste processo reforça o caráter desenvolvimentista de sua ação, tendo em vista o teor nacionalista e positivo que acompanhou o discurso militar, somado ao intenso foco dado na consolidação de um setor industrial na região e de aumento do valor agregado de sua produção. Sem embargo, o avanço deste processo "revolucionário" não ocorreu sem um uso deliberado do monopólio da violência. 
O PA Juma desponta como exemplo paradigmático deste período da história brasileira e, principalmente, da história amazônica, tendo em vista a sua posição enquanto maior assentamento da América Latina no momento de sua criação, em 1982. Podemos entender as expectativas dos atores envolvidos na migração a este local como imagens erguidas em conjunto com o "futuro civilizatório" endereçado pelo Estado. As motivações e significações sobre o território subjacentes à chegada destes atores ao PA Juma nasceram dentro de um discurso moderno, nacionalista, integracionista e capitalista, sustentado e promovido pelo aparato estatal.

\section{4 "TERRAS SEM HOMENS, PARA HOMENS SEM-TERRA": EXPECTATIVAS DOS MIGRANTES SOBRE A OCUPAÇÃO NO PA JUMA}

Entre as 25 categorias analíticas concebidas a partir do conteúdo dos relatos das entrevistas com os atores do PA Juma, uma delas se fez de especial importância para atender ao objetivo traçado para esta seção. Tratam-se da categoria intitulada "Êxodo" e "Criação do Assentamento", as quais agrupam diferentes relatos sobre as expectativas e anseios mais visíveis do migrante durante o seu período de chegada a esse local. Foram agrupados 112 relatos e excertos como pertencentes às duas categorias de análise. Ao todo, a partir destes relatos, pudemos dividi-los em três grandes agrupamentos temáticos, sendo cada um destes condizentes a uma expectativa e significação específica sobre o território de chegada.

Conforme ilustra a Tabela 1, o primeiro desses três grandes agrupamentos refere-se aos migrantes que rumaram ao PA Juma com vistas à exclusivamente capitalizarem-se. Em segundo lugar, estão agrupados os relatos que relacionam a chegada ao PA Juma como uma tentativa de lograr a posse definitiva da terra. Trata-se de indivíduos que, por uma série de razões a serem detalhadas com maior profundidade ao longo da seção, não possuíam terra suficiente em seus locais de origem para a reprodução da estrutura familiar ao longo do tempo. Neste sentido, este agrupamento traz à tona a constituição do "território familiar" (WANDERLEY, 1996) como fator constitutivo da expectativa do migrante, o qual imagina um futuro onde família, trabalho e propriedade se apresentam como tripé sustentador de um modo de vida específico (TEDESCO, 1999). Por fim, em terceiro lugar, agrupamos os relatos que tratam da migração como deslocamento de locais de ocupação "espontânea" para ocupação "planejada", visando gozar da segurança jurídica em relação à documentação da terra que os assentamentos estatais representavam em face aos antigos posseiros. 


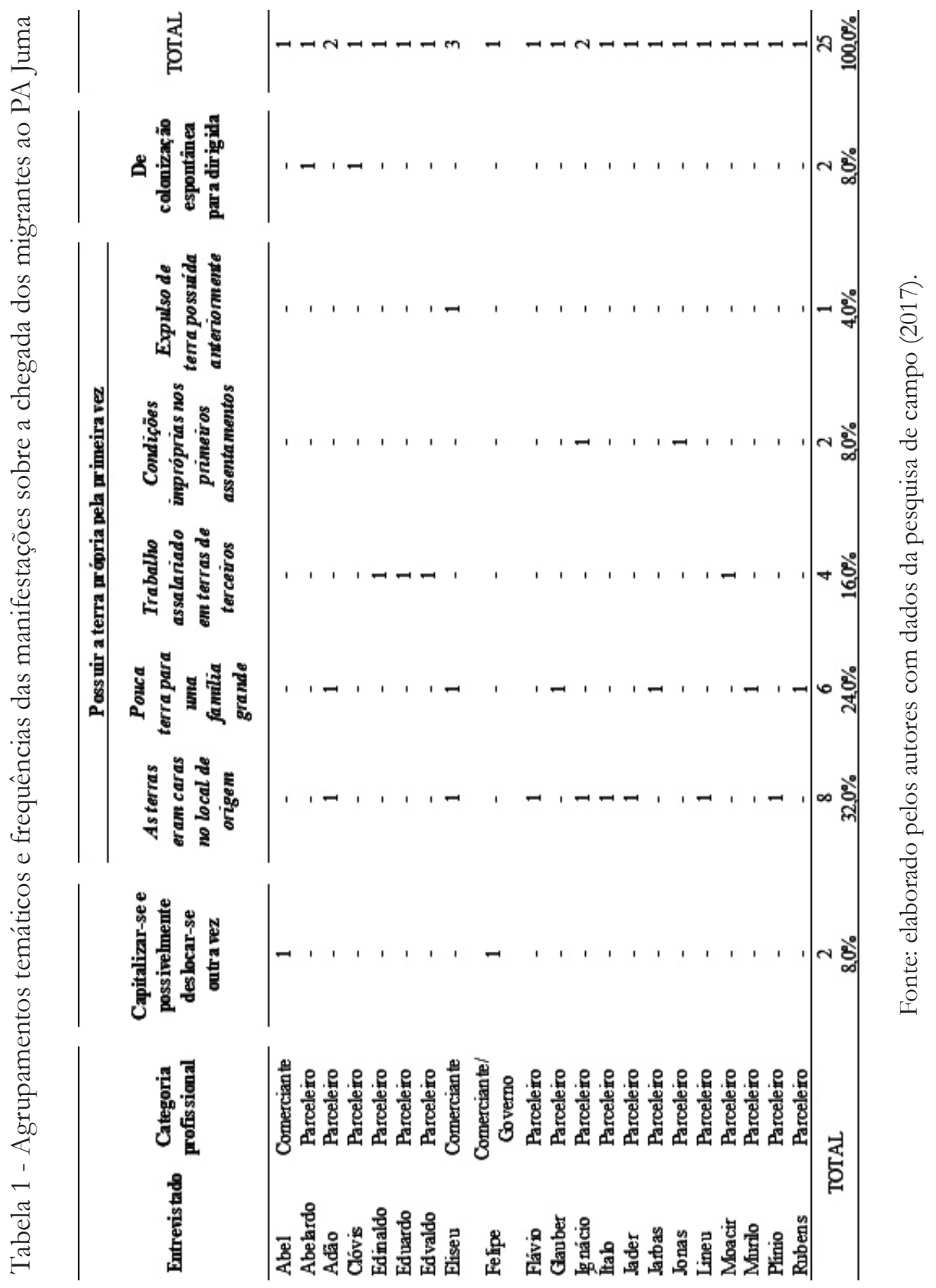


$\mathrm{Na}$ Tabela 1, vale notar que $80 \%$ de todas as manifestações dizem respeito a expectativas calcadas em anseios envolvendo a propriedade da terra e a constituição definitiva do território familiar (macro-agrupamento "possuir a terra própria pela primeira vez”). Este número expressivo de manifestações, por sua vez, pôde ser dividido em cinco subagrupamentos de significações, o que demonstra uma ampla variedade de motivações em jogo durante o momento de migração. Exploraremos com mais afinco, a partir de agora, os três subagrupamentos mais manifestados ${ }^{8}$.

O primeiro contém os relatos que se referiram ao alto preço das terras nos locais de origem dos migrantes, somado ao baixo custo de aquisição das terras no PA Juma, como fatores que estimularam o deslocamento. Este subgrupo foi o mais manifestado entre todos e nos diz muito sobre a estrutura fundiária dos locais de origem. Sendo expressivo contingente dos entrevistados originários da região norte do Rio Grande do Sul, bem como do oeste catarinense e paranaense, os achados das entrevistas reiteram as considerações feitas na literatura sobre como essas regiões são historicamente marcadas pela ampla presença da agricultura familiar, assim como permeadas por diversos conflitos envolvendo a posse da terra, dado os elevados valores de aquisição das mesmas (GEHLEN, 1994; BRUMER; SANTOS, 1997; TEDESCO, 2017).

Para além destes estados, outro expressivo montante dos entrevistados veio do Espírito Santo e do sul da Bahia - locais onde predominam grandes fazendas de cacau e que, por este motivo, também consolidou uma situação de difícil acesso à terra. Por fim, parte dos entrevistados relataram ter vindo de assentamentos mais antigos, localizados em sua maioria no estado de Rondônia. As terras nas regiões de assentamentos deste estado eram trabalhadas há mais tempo do que aquelas no PA Juma, o que implicou, em grande parte, em um maior preço por hectare. Uma vez vendidas, o migrante, ao chegar ao PA Juma, poderia adquirir uma área maior do que aquela anteriormente controlada em seu assentamento de origem.

Acima de tudo, o reduzido valor das terras no PA Juma como fator atrativo e principal sustentador das expectativas do migrante revela a dimensão deste assentamento como uma "fronteira agropecuária". De acordo com parte dos entrevistados, as terras que ainda serão desmatadas para a produção agropecuária possuem preços menores do que aquelas que já foram abertas e que já receberam algum tipo de utilização agropecuária não extrativa. Neste sentido, é importante

\footnotetext{
Ao nosso ver, o quarto e o quinto subgrupos trazem motivos secundários no que diz respeito às expectativas em jogo no momento da migração, dado o reduzido grau de frequência que suas manifestações obtiveram.
} 
notar como a imagem de um território "híbrido", onde "natureza" e "produção agropecuária" coexistem, constitui-se como atrativo relevante, pois implica diretamente em um reduzido custo de aquisição das mesmas?.

O segundo dos cinco subgrupos traz à tona as questões envolvendo a viabilidade da reprodução da estrutura familiar nas terras de origem. Ao todo, $24 \%$ das manifestações dos entrevistados estiveram atreladas a este tema, relembrando histórias sobre como as extensas famílias nas regiões de origem representavam um dilema à reprodução social, principalmente se tomarmos em consideração a prevalência do sistema de partilha igualitária da terra entre os filhos nesses locais (SCHNEIDER, 1999). As claras limitações deste modelo estimularam as sucessivas gerações a buscarem suas terras em outras regiões do Brasil, uma vez que o elevado preço nos locais mais populosos do país impedia a aquisição de áreas nas adjacências da propriedade familiar original ${ }^{10}$.

Com isso, os primeiros migrantes instalados no PA Juma vislumbraram estabelecer um território familiar, fato não mais possível em suas regiões de origem. Vemos esta expectativa como um importante resultado da pesquisa, à medida que se associa com o discurso estatal de significar a região amazônica como uma região de "oportunidades socioeconômicas", de avanço da agropecuária e da produção em larga escala sobre áreas previamente ocupadas por florestas. Em última instância, o PA Juma desponta como a "última fronteira" ao migrante, onde este tentará consolidar um projeto de vida que não fora possível em suas respectivas regiões de origem.

O terceiro subgrupo trata diretamente do tripé produção-famíliapropriedade, o qual sustenta o conceito de território familiar e resume, em boa medida, o que o migrante esperava com a sua ida ao PA Juma. Neste subgrupo, estão agrupados relatos que justificam a migração como uma tentativa de fugir do trabalho assalariado no campo, com vistas à aquisição da própria terra, onde então o migrante terá pleno poder decisório sobre a produção rural e utilização do produto gerado a partir do emprego da força de trabalho familiar. De maneira oposta a esta ambicionada conjuntura, o trabalhador assalariado devolve expressiva parte do produto gerado pelo seu trabalho ao seu empregador, bem como está condicionado a uma relação de trabalho desvinculada do trabalho familiar e da propriedade individual.

9 As dinâmicas envolvendo o custo de aquisição das terras é ainda mais apelativa àqueles que chegaram ao PA Juma como compradores de terras, isto é, sem a intermediação do INCRA - o que foi o caso de seis das 23 famílias rurais entrevistadas.

10 Para Almeida (1992), os assentamentos rurais na Amazônia reduziram as pressões populares sobre a propriedade de terra, postergando qualquer possibilidade de reforma agrária a partir da redistribuição fundiária. Conforme ressalta Ianni (1979), a colonização configurou-se como o principal plano do Governo militar para evitar outro tipo de reforma agrária que implicasse em mudanças na estrutura agrária perpetrada nas regiões de origem dos colonos. 
Atuar como trabalhador assalariado - seja este parceiro, meeiro, capataz ou funcionário temporário, por exemplo - impacta diretamente no planejamento familiar de longo prazo. Esta condição não somente resume uma conjuntura contrária àquela aspirada pelo então migrante, como também consolida uma situação de constantes desafios ao sustento material de toda a família, mediante os reduzidos salários pagos a pessoas empregadas nesses termos e a constante ameaça do desemprego. Nesse sentido, o sustento material de todos os componentes familiares desponta como importante expectativa envolvida na migração ao PA Juma, onde este espaço passa então a ser entendido como oportunidade de gozar de uma nova relação de trabalho com a terra. Edinaldo, por exemplo, um dos entrevistados durante a pesquisa de campo, sustentou as suas expectativas envolvendo a sua vinda a Apuí nesta direção:

Rapaz, o negócio é que eu saí da Bahia pra vir pra cá não é por nada não, porque eu vivia trabalhando pra um e pra outro. Eu tinha família, acompanhado por sete filhos, trabalhava um dia pra um, um dia pra outro e não dava pra nada. E o meu plano de vir pra cá foi de conseguir uma terra pros meus filhos ir crescendo, ir casando e ir ficando perto de mim (Informação verbal) ${ }^{11}$.

O amplo número de manifestações envolvendo a fuga do trabalho assalariado como fator motivador à migração ilustram a importância de questões como a emancipação, o planejamento familiar e a economia doméstica na decisão do migrante em se deslocar ao PA Juma. Com isso, o assentamento em questão demonstra ser um espaço que não somente está mergulhado nas expectativas do migrante de ascensão e emancipação social, mas também imbuído de significações que compartilham do discurso estatal sobre a Amazônia como um território de "potencialidades econômicas" a serem usufruídas pelos atores de sua colonização. Este achado reforça, na verdade, a consideração feita por Velho (2009) sobre as "fronteiras" como espaços almejados de ascensão social, isto é, de expansão da composição de capital familiar, somado a aquisição da terra própria e à mudança na ocupação profissional - e.g., de trabalhador assalariado para proprietário de terra.

Entretanto, envolvidos em uma trama de aspirações socioeconômicas resumidas nos três subgrupos analisados, os migrantes que ocuparam o PA Juma observaram, ao longo das últimas duas décadas, reais desafios à efetiva consolidação do imaginário da fronteira como terra de oportunidades únicas. Frizo (2019) ressalta uma série de indicadores que ilustram a ineficiência do

11 Informação concedida por Edinaldo, em fevereiro de 2017. 
projeto de assentamento e de sua gestão pública por parte dos órgãos a ele atrelados, tais como o INCRA e o Instituto de Desenvolvimento Agropecuário e Florestal do Amazonas (IDAM), em garantir, de fato, a posse da terra às famílias assentadas, bem como a viabilidade econômica das operações produtivas ocorridas nos limites da propriedade familiar ${ }^{12}$.

A inviabilidade do discurso desenvolvimentista e de seus componentes institucionais terem promovido o efetivo ganho socioeconômico aos migrantes não opera, contudo, como fator disruptivo para a emergência de um novo modo de significação e apropriação simbólica do território. Em verdade, a fronteira enquanto constructo simbólico segue demonstrando uma latente capacidade de reprodução, haja vista que, dentre os entrevistados desta pesquisa, abundam aspirações intimamente atreladas ao conjunto de ideias, projeções e imagens criadas sobre o território amazônico ainda no período ditatorial. Se, por um lado, a narrativa desenvolvimentista não mais suscita movimentos migratórios de larga escala e tampouco projetos estatais de grande magnitude no sul amazonense, do outro ela permanece intrinsicamente incrustada no imaginário rural da região.

Com isso, narrativas alternativas que emergem localmente trazem consigo componentes importantes do discurso da fronteira, a fim de se legitimarem socialmente para buscar, de alguma forma, reorientar os modos de apropriação simbólica do território e das formas de apropriação econômica de seus elementos naturais que se sucedem. É o caso, por exemplo, da atuação de ONG ambientalistas, as quais, desde 2008, visam reduzir o ritmo de desmatamento no município de Apuí por meio da implementação de uma economia de baixo carbono, sustentada em sistemas agroflorestais e silvipastoris. No entanto, este conjunto de organizações pouco produziu em termos de engajamento social nos seus primeiros projetos de intervenção essencialmente ambientalistas. Na verdade, foi somente a partir da adoção de um discurso próximo da ideia de "modernização ecológica" (MOL,

12 Segundo o autor, o PA Juma é configurado por um conjunto de características que ilustram o atual processo de crise das expectativas ficcionais construídas pelo Estado e incorporadas pelos atores envolvidos na ocupação deste território. São algumas das dimensões destacadas pelo autor a queda real de aproximadamente um terço na renda anual das famílias rurais, se comparado os anos de 2014 e 2006; a inexistência de títulos definitivos de propriedade para mais de $90 \%$ das famílias que ocuparam a região; o foco excessivo e restrito do IDAM em políticas de fomento à pecuária, olvidando-se de contemplar outras políticas de assistência técnica em sua atuação local; uma latente e histórica conjuntura de monopsônio, onde um grupo restrito de compradores de gado de corte e - ainda mais restrito - de mercadorias agrícolas reduz o poder de barganha das famílias rurais e, com isso, o preço de venda de seus produtos; o isolamento social, caracterizado pelas reduzidas taxas de engajamento da população em organizações civis, bem como à dificuldade de locomoção e escoamento pelas estradas locais. Ao todo, somadas em conjunto, tais dimensões explicam a razão pela qual o PA Juma possui somente $20 \%$ de sua capacidade total ocupada, bem como por qual motivo o município de Apuí foi o único em toda a microrregião do rio Madeira a presenciar um decréscimo em sua população rural entre os anos de 2010 e 2000.

Novos Cadernos NAEA • v. 23 n. $1 \cdot$ p. $35-58 \cdot$ jan-abr 2020 
2000; CARNEIRO; ASSIS, 2015), quando pautas ambientalistas passaram a ser coadjuvantes mediante o crescente protagonismo de conceitos como "cadeias produtivas", "produtividade", "desenvolvimento sustentável" e "tecnologia", que o conjunto de enquadramentos mobilizados pelas $\mathrm{ONG}$ para a produção de engajamento entre os atores locais demonstrou ser efetivo (FRIZO, 2019), recuperando anseios antigos de fixação, melhoria de vida e constituição do território familiar.

\section{CONSIDERAÇÕES FINAIS: ZEITGEIST E TRANSFORMAÇÃO SOCIAL}

Longe de tratarmos os interesses das famílias apuienses como uma razão atemporal e universal, busca-se entender ao longo deste artigo como suas expectativas emergem como produto sociopolítico, isto é, como conjunto de aspirações que nasce dentro e amparado pelo discurso estatal construído para a região amazônica nas décadas de 1960, 70 e 80. A comparação entre os dados coletados nas entrevistas e o material analisado nos dois livros selecionados nos permite apontar nesta direção, revelando que as "potencialidades socioeconômicas" que animaram as migrações se resumem, satisfatoriamente, na conquista da terra própria, dado que esta insere o migrante em uma nova relação de produção, retirando-o da condição de trabalhador assalariado e posicionando-o como proprietário. Essa nova conjuntura socioeconômica cristaliza-se na ideia da constituição do território familiar, espaço onde o tripé família-produção-propriedade sustenta a reprodução social.

Por trás de tamanho afinco envolvendo o deslocamento em massa a estes espaços e, em específico, ao PA Juma, reside uma profunda desigualdade fundiária nas regiões de origem dos migrantes, a qual atirou populações tradicionalmente desapossadas a regiões onde a agropecuária de larga escala ainda era inexistente. O fenômeno analisado ao longo do artigo não foge, portanto, do que Ianni (1979) e Tavares dos Santos (1991) descreveram outrora sobre a colonização amazônica como um projeto de "contra-reforma agrária", uma vez que retardou qualquer urgência e/ou tentativa de redistribuição das propriedades rurais nas regiões Sul, Sudeste e Nordeste do país.

A migração foi acompanhada de um projeto de utilização social da terra orientada à produção agropecuária em larga escala - um modelo de desenvolvimento rural importado para uma Amazônia marcada pela produção extrativista. Com efeito, presenciou-se a intensa implementação de procedimentos institucionalizados que propiciaram o desmatamento e a degradação ambiental 
da Amazônia, onde florestas foram sendo gradativamente substituídas por empreendimentos agropecuários. No caso do PA Juma, por exemplo, notou-se uma gradativa expansão da pecuária de corte em seu modo extensivo nas últimas três décadas (CARRERO et al., 2014), substituindo cultivares como o arroz, milho e feijão, plantados em grandes quantidades somente nos anos de $1980 \mathrm{e}$ 1990 (FRIZO; NIEDERLE, 2019). Não à toa, o município de Apuí foi incluído, em setembro de 2017, pelo Ministério do Meio Ambiente na lista prioritária de combate ao desmatamento (BRASIL, 2017).

Entretanto, conforme vimos, não é exagero questionar-se até que ponto o PA Juma - e, de uma maneira geral, os assentamentos erguidos ao longo do regime militar - cumpriu com as expectativas levantadas entre os atores envolvidos em sua ocupação. Ao constatarmos como a ideia de "fronteira" constitui-se como importante instituição cultural-cognitiva entre os atores locais, o presente artigo abre espaço para futuras investigações compreenderem como novas propostas de significação do território amazônico seriam possíveis, tendo em vista a inexorabilidade do entendimento da Amazônia como "fronteira da modernidade" e "fronteira agropecuária". Autores imersos na tradição do institucionalismo histórico (ACEMOGLU; ROBINSON, 2012; NORTH, 1983) já demonstraram em outros estudos como trajetórias socioeconômicas são dificilmente alteradas, em especial devido à latência de uma série de instituições consolidadas ao longo da história social, observando assim uma "dependência do caminho" já traçado historicamente.

Isto fica claro no modo como entidades ambientalistas da região passaram a dialogar com significações historicamente constituídas no seio da aspiração desenvolvimentista, i.e., constituídas sob um discurso modernizante, positivista e nacionalista. Estes novos atores tentaram fazer ecoar a diversos grupos sociais uma proposta de apropriação e exploração dos recursos naturais que vai na contramão daquela inaugurada pela visão da Amazônia como território de "potencialidades econômicas". No entanto, a ineficácia de seus discursos as tem incitado a incorporar a narrativa modernizante, o que se expressa em projetos cada vez mais voltados para uma perspectiva de "modernização ecológica" (FRIZO, 2019; CARREIRO; ASSIS, 2015). A “culturalização" (ZHAO, 2010) dos projetos destas entidades - ou seja, sua readequação às expectativas ficcionais dos atores locais - sugere um processo cumulativo de experiências sociais de construção e afirmação de significações, aspirações, ideias e símbolos construídos sociopoliticamente no passado, e cuja mudança, ao menos neste contexto social, ratifica o lento padrão das transformações da sociedade brasileira em face do "poder do atraso" (MARTINS, 1994). 


\section{REFERÊNCIAS}

ACEMOGLU, D.; ROBINSON, J. Why nations fail: the origins of power, prosperity and poverty. New York: Crown Publishing Group, 2012.

ACSELRAD, H. (org.). Conflitos ambientais no Brasil. Rio de Janeiro: Relume Dumará: Fundação Heinrich Böll, 2004.

ALMEIDA, A. L. O. Colonização dirigida na Amazônia. Instituto de Pesquisa Econômica Aplicada, Brasília, n. 135, 1992.

ANDRADE, J.W. Planos de desenvolvimento: SUDAM. In: LIMA, A. A. A. et al. Problemática da Amazônia. Rio de Janeiro: Biblioteca do Exército, 1971. p. 149-172. (Coleção Gen. Benício, v. 90, n. 415).

ARAÚJO, A.; NEVES, M. V. Soldados da borracha: os heróis esquecidos. São Paulo: Irê Brasil e Escrituras Editora, 2015.

BARDIN, L. Análise de conteúdo. Lisboa: Edições 70, 1971.

BATISTA, D.C. Inventário científico da Amazônia. In: LIMA, A. A. A. et al. Problemática da Amazônia. Rio de Janeiro: Biblioteca do Exército, 1971. p. 271-300. (Coleção Gen. Benício, v. 90, n. 415).

BECKERT, J. Imagined futures. Cambridge: Harvard University Press, 2016.

BRASIL. Decreto-Lei No 288, de 28 de fevereiro de 1967. Altera as disposições da Lei número 3.173 de 6 de junho de 1957 e regula a Zona Franca de Manaus. Brasília, DF: Presidência da República, [1967]. Disponível em: http://www. planalto.gov.br/ccivil_03/Decreto-Lei/Del0288.htm. Acesso em: 04 abr. 2020.

BRASIL. Ministério do Meio Ambiente. Lista de municípios prioritários da Amazônia. Brasília, DF, 2017. Disponível em: https://www.mma.gov.br/ informma/item/8645-lista-de-munic $\%$ C 3\%ADpios-priorit $\% \mathrm{C} 3 \% \mathrm{~A} 1$ rios-daamaz\%C3\%B4nia. Acesso em: 04 abr. 2020.

BRUMER, A.; SANTOS, J. V. T. Tensões agrícolas e agrárias na transição democrática brasileira no final do século XX. São Paulo em Perspectiva, São Paulo, v. 11, n. 2, p. 3-14, 1997.

CARNEIRO, M. S.; ASSIS, W. S. O controle do desmatamento na Amazônia como um processo de modernização ecológica: a experiência do projeto Município Verde. Repocs, São Luís, v. 12, n. 24, p. 53-76, jul./dez. 2015. 
CARRERO, G.; ALBUJA, G.; FRIZO, P. G. A.; HOFFMANN, E.; ALVES, C.; BEZERRA, C. Caracterização da cadeia produtiva de carne bovina no Amazonas com ênfase no município de Apuí. Manaus: Instituto de Conservação e Desenvolvimento Sustentável do Amazonas, 2014.

CAVALCANTE, R. B.; CALIXTO, P.; PINHEIRO, M. M. K. Análise de conteúdo: considerações gerais, relações com a pergunta de pesquisa, possibilidades e limitações do método. Inf. \& Soc.: Est., João Pessoa, v. 24, n. 1, p. 13-18, jan./abr. 2014.

COSTA, F. A. Formação agropecuária na Amazônia: os desafios do desenvolvimento sustentável. Belém: NAEA, 2012.

DIMAGGIO, P. J; POWELL, W. W. A gaiola de ferro revisitada: isomorfismo institucional e racionalidade coletiva nos campos organizacionais. RAE-Revista de Administração de Empresas, [S. l.], v. 45, n. 2, p. 74-89, 2005.

ELIAS, N. O processo civilizador. Rio de Janeiro: Jorge Zahar, 1994. v. 1.

ESCOBAR, A. El postdesarollo como concepto y prática social. In: MATO, D. (org.). Políticas de economía, ambiente y sociedad en tiempos de globalización. Caracas: Facultad de Ciencias Económicas y Sociales, Universidad Central de Venezuela, 2005. p. 17-31.

FONSECA, P. C. D. Gênese e precursores do desenvolvimentismo no Brasil. Pesquisa e Debate, São Paulo, v. 15, n. 2, p. 225-256, 2004.

FRIZO, P. Os parce(le)iros da Amazônia: fundamentos institucionais para uma economia da floresta em pé. São Paulo: Annablume, 2019.

FRIZO, P.; NIEDERLE, P. Determinações do Estado sobre os moldes de ocupação e apropriação da terra: a "presença ausente" do INCRA na emergência da pecuária extensiva no sul do Amazonas. Terceira Margem Amazônia, Manaus, v. 12, n. 4, p. 12-31, 2019.

FURTADO, C. O mito do desenvolvimento econômico. 3. ed. Rio de Janeiro: Paz e Terra, 2001.

GEHLEN, I. Estrutura, dinâmica social e concepção sobre a terra no Meio Rural do Sul. Cadernos de Sociologia, Porto Alegre, v. 6, n. 6, p. 154-176, 1994.

GOFFMAN, E. Os quadros da experiência social: uma perspectiva de análise. Petrópolis: Vozes, 2012.

HIRSCHAMN, A. O. Estratégia do desenvolvimento econômico. Rio de Janeiro: Fundo de Cultura, 1961. 
HIRSCHAMN, A. O. Auto-subversão: teorias consagradas em xeque. São Paulo: Companhia das Letras, 1996.

IANNI, O. Colonização e contra-reforma agrária na Amazônia. Petrópolis: Vozes, 1979.

IDESAM. Entendendo as queimadas e incêndios florestais em Apuí, Sul do Amazonas. IDESAM, [S. l.], 2019. Disponível em: https://idesam.org/ publicacao/nota-emergencial-apui.pdf. Acesso em: 04 abr. 2020.

MARSENO, A. M. A Amazônia e nós. Rio de Janeiro: Biblioteca do Exército, 1971. (Coleção Gen. Benício, v. 94, n. 419).

MARTINS, J. S. O poder do atraso: ensaios de sociologia da história lenta. São Paulo: Hucitec, 1994.

MOL, A. P. A globalização e a mudança dos modelos de controle e poluição ambiental: a teoria da modernização ecológica. In: HERCULANO, S.; PORTO, M. F. S.; FREITAS, C. M. (orgs.). Qualidade de vida e riscos ambientais. Niterói: EDUFF, 2000, p. 267-280.

NORTH, D. C. Structure and change in economic history. New York: W. W Norton \& Company, 1983.

SCHNEIDER, S. Agricultura familiar e industrialização. Pluriatividade e descentralização industrial no Rio Grande do Sul. Porto Alegre: Editora da UFRGS, 1999.

SCOT'T, W., S. Institutions and organizations: ideas, interests and identities. 4. ed. New York: SAGE Publications, 2014.

TAVARES DOS SANTOS, J, V. As novas terras como forma de dominação. Lua Nova, São Paulo, v. 23, p. 67-82, mar. 1991.

TAVARES DOS SANTOS, J. V. Violências e dilemas do controle social nas sociedades da "modernidade tardia". São Paulo em Perspectiva, São Paulo, v. 18, n. 1, p. 3-12, 2004.

TEDESCO, J. C. Terra, trabalho e família: racionalidade produtiva e ethos camponês. Passo Fundo: Editora da Universidade de Passo Fundo, 1999. v. 1.

TEDESCO, J. C. Conflitos agrários no Norte Gaúcho: dimensões históricas. Porto Alegre: EST Edições, 2017. 
VELHO, O. G. Capitalismo autoritário e campesinato: um estudo comparativo a partir da fronteira em movimento. Rio de Janeiro: Centro Edelstein de Pesquisas Sociais, 2009.

WANDERLEY, M. N. B. As origens históricas do campesinato brasileiro. In: ENCONTRO ANUAL DA ASSOCIAÇÃO NACIONAL DE PÓSGRADUAÇÃO E PESQUISA EM CIÊNCIAS SOCIAIS, 20., 1996, Caxambu. Anais [...]. Caxambu: ANPOCS, 1996. p. 1-16.

ZHAO, D. Theorizing the role of culture in social movements: illustrated by protests and contentions in modern China. Social Movement Studies, [S. l.], v. 9, n. 1, p. 33-50, 2010. 